\title{
Castoriadis y el REgreso de lo religioso. Auto-Alteración de LA SOCIEDAD Y META-NORMA ${ }^{1}$
}

\author{
Rafael Miranda
}

Resumen: En este artículo desarrollo algunas nociones provenientes del cuerpo conceptual de Cornelius Castoriadis, para abordar el fenómeno religioso. Inscribo dicho aporte aplicándolo a la crítica de lo que se ha dado en llamar el regreso de lo religioso. Primero ilustro, a título de caso testigo, el lugar que las cuestiones religiosas tienen en la actual campaña presidencial en Estados Unidos. En segundo término abordo el papel que, bajo el reclamo de la ética, han desempeñado los representantes del pensamiento posmoderno. Dedico en este apartado una atención particular al uso que Levinas hace del término alteridad y a los efectos de su popularidad en el proceso de repliegue al espacio privado y de denegación de la política en medios franceses, principalmente. Introduzco la relación instituyenteinstituido que supone el fenómeno religioso. Una reflexión más, en el plano de la ontología del autor, es igualmente abordada, en particular respecto al tiempo como alteridad. Finalmente, basándome en esos contenidos, expongo de modo concentrado las nociones núcleo de la propuesta castoridiana para descifrar el fenómeno religioso. Propuesta fundada en una lectura, despojada de determinismo, del descubrimiento por Freud del imaginario.

Palabras clave: imaginario, institución, desencanto de la política, heteronomía, regreso de lo religioso, transferencia institucional, meta-norma, comunitarismo, auto-alteración explicita, infrapoder.

Rafael Miranda, Cornelius Castoriadis/Agora International, web: www. agorainternational.org; correo electrónico: aguatint@wanadoo.fr; aguatint@ hotmail.com.

98
Abstract: This article developments some knowledge about the conceptual body of Cornelius Castoriadis's, to the approach to religious phenomenon. I present this contribution with its application to the critic who has called for a return of the monk's ideas. First I illustrate, as a case witness, the place that the religious questions have had in the present presidential campaign in the United States. In second term I attack the paper that has played, under the call for ethics, the representatives of post-modern thought. I dedicate in this section particular attention to the use that Levinas makes of the term alteridad and to the effects of its popularity in the process of creating private space and refusal to use the policy in average French media. I introduce the instituyente-instituted relation that presupposes religious phenomenon. One more reflection in the ontology of the author is equally boarded, in the individual with respect to time like alteridad. Finally, basing me on those contents, I write in a brief, concentrated way, the nucleus of knowledge of the castoridian proposal to decipher religious phenomenon. A proposal, founded on a reading, divested of determinism, is presented of the discovery by Freud of the imaginary.

Key words: imaginary, institution, disillusion of the policy, heteronomy, return of the monk, institutional transference, put-norm, comunitarism, auto-alteration specifies, to be able

Enviado a dictamen: 09 de febrero de 2008 Aprobación: 08 de mayo de 2008. 


\section{El fenómeno religioso y el proyecto de autonomía}

L a segunda mitad del siglo XX en Occidente se vio envuelta en un descrédito de certezas antaño incuestionables. La masiva repercusión de ese proceso se tradujo en la privatización y fue vinculada, por algunos analistas, con lo que se ha dado en llamar el regreso de lo religioso. Simultáneamente a las formas en que la culpa y el arrepentimiento de los occidentales se iban plasmando en el deconstruccionismo, el surgimiento de la consigna de dicho regreso nos ofrece la oportunidad de retomar una reflexión profunda en torno a la génesis del fenómeno religioso.

De entrada digamos, parafraseando a Castoriadis, que dicho regreso, más que una realidad, expresa un deseo por asimilar de nuevo lo que podría estar inscrito en el ser y el sentido, en el origen del mundo y en el origen de la institución social. Este esfuerzo de asimilación recorrería, en el último cuarto del siglo pasado, desde enteros sectores del espectro filosófico heredado, hasta llegar incluso a la denominada muerte de la filosofía y del sujeto.

De modo contrastante y desde una postura radicalmente crítica del occidente capitalista, la vía abierta por Castoriadis monta su hipótesis sobre las dos significaciones imaginarias sociales (SIS) ${ }^{2}$ fundadoras de la cultura greco occidental. Por un lado, la sis de la pseudo-racionalidad capitalista, con sus efectos de des-socialización y de debacle ecológica, será objeto de una crítica radical por parte del autor (Castoriadis, 1982, 1992a, 1992b y 1992c). Por el otro, la SIS del valor de la autonomía será objeto de replanteamiento, como un proyecto inacabado de sociedad autónoma. Lo que se denomina Auto-nomos, ser el origen de la propia ley, ${ }^{3}$ convive en tensión en la base de una sociedad que optó por dictar a la ciudad, ${ }^{4}$ a la comunidad política, las leyes desde fuera. Una sociedad que optó por salvar a la humanidad de sí misma, inaugurando así esa forma de dominación que es la filantropía en sentido moderno. El valor de la autonomía, en contraste, SIS cuyos orígenes germinales estarían en la ruptura de la clausura representada por el nacimiento de la democracia y de la filosofía en la Atenas clásica, había sido marginal y esporádicamente retomado en la tradición de Occidente.

En el contexto de esta tradición, ahí donde el fenómeno religioso ha sido consignado a la esfera de lo privado, principalmente en aquellas sociedades en donde la secularización se ha enraizado, la estadística disponible muestra que, en efecto, el regreso de lo religioso es inexistente. De modo paralelo, en los márgenes del mundo greco-occidental, las sociedades basadas en la pertenencia comunitaria sobreviven a la globalización y al aumento de la insignificancia, refugiadas en la heteronomía. En estas sociedades no se puede hablar de un regreso, porque las pertenencias religiosas no han dejado de estar presentes en la regulación de la vida social.

Son las implicaciones de lo dicho lo que me ocupa en el presente escrito; implicaciones que abordo según el procedimiento y el orden de exposición siguiente.

\section{1.-Procedimiento}

El orden en el que desarrollo las implicaciones del llamado regreso de lo religioso contempla el análisis de dos casos, ilustrativos respecto a cómo cada uno de esos dos pueblos, el estadounidense y el francés, viven la religión. El procedimiento que propongo va del análisis de la pertenencia religiosa de un pueblo, a la manera en que el pueblo es representado por la religión como institución. La religiosidad en los Estados Unidos y el importante papel que ésta desempeña en la actual campaña política, caso que presento en un apartado, tienen en mi exposición el carácter de caso testigo. Este caso testigo lo valoro a la luz de los matices emergentes que la vieja religiosidad, particularmente en Francia, ha venido adquiriendo en las últimas décadas. En el segundo parágrafo profundizo respecto a la popularidad que ha cobrado, particularmente en medios de la llamada izquierda iluminada, el pensamiento de Emmanuel Levinas. 
En un tercer apartado planteo la representación de un pueblo hecha por la institución religiosa. Esto me permite introducir, con la derrota de la guerra del Peloponeso y de sus efectos para la Atenas democrática, el origen lejano del deseo de dictar las leyes a la comunidad política y de hacerlo desde sus fronteras. La cercanía del efecto perverso de dicha guerra, con la esencia del fenómeno religioso, es, desde Castoriadis, inmensa. Esa cercanía me va a permitir puntualizar sobre las éticas religiosas, como lugar de compromiso, entre el deseo de religión y la religión como institución social-histórica.

Un cuarto apartado está dedicado a dejar sentados los términos en que la clausura como sentido ${ }^{5}$ permite soldar, en el imaginario, el tiempo de una sociedad; tiempo de una sociedad que se convierte en tiempo cíclico y en calendario, en repetición de lo mismo, dando la espalda al tiempo como alteridad-alteración y al quehacer de la sociedad como auto-creación. El Tiempo de una sociedad sobre el cual vienen socializados-fabricados los sujetos que a esa sociedad corresponden y que, mal que bien, garantizan su permanencia.

Tengo a la vista en esta parte esa máxima según la cual el elenco infinito de formaciones de compromiso en el plano de lo simbólico, que han brindado recurso a la psique y a la sociedad para escamotear la posibilidad de la creación-destrucción, estaría dado por las formas inagotables de la heteronomía, la ley dictada por el otro. Osemos contradecir a Aristóteles, diría Castoriadis (2006: 289); lo que la psique y la sociedad buscan y necesitan no es el saber sino la creencia. La ley dictada por el otro se cristaliza en las metanormas sucesivas, llámense "voluntad divina", "leyes del mercado" o "leyes de la historia".

Los parágrafos descritos me darán paso a lo que considero el núcleo duro del fenómeno religioso, mismo que trato en un quinto apartado: se trata de la clausura como sentido y de la condición de para sí que todo organismo supone. La vocación para el ocultamiento de la alteridad de dicha clausura, apenas es verificada, se encuentra sujeta al empuje creador del imaginario radical.
En un sexto apartado, siguiendo puntualmente el itinerario referido a la evolución del mundo grecooccidental, expondré de modo somero las condiciones en las que la eclesia, la asamblea, deviene la Iglesia, la institución. En este contexto problematizaré sirviéndome de la noción de transferencia institucional, ${ }^{6}$ la relación de renuncia a la propia autonomía que viene aparejada a la aceptación de toda heteronomía. Voy a concluir provisionalmente con un tratamiento apenas indicativo en torno a las limitantes en el campo de la filosofía política, de la división corriente entre sociedad civil y Estado. Este tratamiento va a permitirme dimensionar la actual ocupación masiva del espacio público por la expresión de comunitarismos de pertenencia.

Para cerrar haré un repaso del esquema castoridiano respecto a la división de la sociedad en tres momentos -oikos, agora, eclesia - Veremos cómo ese esquema nos ofrece una vía alterna para entender la noción de infrapoder y para entender - desde una postura que concede relevancia política a la cultura- su contundencia respecto al proyecto de autonomía.

\section{2.- Contexto de un desencanto}

En la inmediata posguerra en Francia, a raíz del curso que tomaron los acontecimientos que se dieron durante la Guerra de Argelia (1958-1962), la cultura política de la izquierda oficial se vio puesta en entredicho severamente. Además, en los medios críticos del estalinismo ${ }^{7}$ se perfilaba ya - a través de lo que, con Lourau (1974 y 1980), denominamos el efecto analizante 8 - un primer nivel de esclarecimiento del fenómeno burocrático y una primera caracterización de dicha sociedad, en su calidad de sociedad totalitaria.

En el contexto que rodeó la escisión (1963) del grupúsculo de extrema izquierda Socialisme ou Barbarie, imperaba ya un profundo desencanto. Este desencanto se convertiría en emblemático durante las tres décadas sucesivas. Jean François Lyotard (1924-1998) dio cuenta de este estado de cosas a través de la formulación de 
su filosofía del deseo. Al interior de ésta se encuentra una crítica del mundo militante; crítica que equipara esta cultura politica con una religión. Esta crítica traería consigo el que el leído autor se fuera alejando paulatinamente del marxismo y del psicoanálisis.

En el origen del desacuerdo que produjo la escisión mencionada, Lyotard acusaba de abandonar esa tradición a otros miembros de dicho grupúsculo (Gottraux, 2002: 144; Castoriadis, 2006: 31 y sigs.). En particular Castoriadis (1922-1997) había sido objeto de ese reproche. En su texto La condition postmoderne (1979), Lyotard descarta la posibilidad de un universal y aboga, en contraposición, a favor de las minorías. Es pues en este contexto donde encontramos un primer estadio del denominado regreso de lo religioso.

Del proceso descrito se desprenderá una serie de críticas y de tomas de posición en las que, no pocas veces, se culpaba al occidente diabólico de todos los males de la humanidad. Las ideas de la Ilustración y el positivismo científico, partes fundadoras de lo que Castoriadis considera (2006: 281) una sociedad a la deriva, habían sido el blanco de ataques diseñados por autores identificados con la postura posmoderna.

Castoriadis, por otro lado, desde un posicionamiento relativamente marginal, orientó su reflexión hacia la tradición filosófica heredada, y la denominó (2002: 96) como una teología racional. El determinismo, como otra meta norma $a^{9}$ correspondiente a dicha tradición, que anunciaba ya la máxima hegeliana todo lo que es real es racional, lo había llevado a reconocer, en dicha tradición, las huellas de la clausura ante la alteridad radical. ${ }^{10}$

A partir de una toma de posición, con la que se va a deslindar diametralmente de la crítica posmoderna ${ }^{11}$ Castoriadis emprende una refundación del pensamiento respecto al fenómeno religioso. Antes de pasar a describir esa refundación en sus pormenores, se ilustra, en el apartado siguiente y en el parágrafo sucesivo, el material sobre el que aplicamos los elementos de análisis.

\section{La religión de un pueblo}

En un artículo recientemente publicado por el periódico LeMonde, Corine Lesnes (2007) presenta la manera cómo la sociedad estadounidense vive la religiosidad. La autora da cuenta del peso de las cuestiones teológicas en la actual campaña presidencial en los Estados Unidos, tanto en el campo republicano como en el demócrata. La atmósfera que se describe hace pensar en una mezcla entre el uso de la religiosidad, como recurso de campaña en manos de políticos profesionales astutos, y las expresiones de convicciones visiblemente sentidas. El debate, que se esperaba reñido respecto a cuestiones como la guerra en Iraq o la política económica, se ha visto eclipsado por discusiones acaloradas sobre temas bastante insólitos para un observador externo. La discusión entre mormones y evangélicos, respecto no a la próxima reencarnación de Jesucristo, ante la cual hay total consenso, sino respecto al estado de la Unión en donde esa reencarnación tendrá lugar, ocupa momentos álgidos de las reuniones públicas.

No hace falta probar que en la vida cotidiana del pueblo estadounidense la cuestión teológica, al menos declarativamente, está muy presente. Desde el lema in god we trust, que acompaña los billetes verdes, hasta las plegarias en las mega churches que reúnen decenas de miles de feligreses, esa presencia se antoja masiva. No obstante lo anterior y contrario a lo que pudiera pensarse, la observancia de las prácticas religiosas en esa sociedad va en disminución.

La fuente referida cita un estudio del Pew Research Center $^{12}$ que llama la atención sobre el hecho de que la plegaria, como momento considerado importante de la cotidianeidad, reporta un significativo descenso, en las encuestas de opinión.

La misma disminución se verifica respecto al número de personas que declaran que nunca dudan de la existencia de Dios. Según ese estudio, la tendencia al aumento de la práctica religiosa que se había registrado en los años noventa se estaría invirtiendo. Paralelamente, 
el número de personas que se declaran agnósticas va en aumento, en particular entre los jóvenes, a pesar de que su porcentaje (12\%) es todavía muy reducido.

Volviendo a la campaña presidencial, en particular en el campo republicano, los candidatos han debido responder a cuestiones que, en un contexto secular, son consideradas propias de la esfera privada. Llama la atención aquella que se dirime respecto a la creación por Dios del mundo en seis días, hace seis mil años. En ninguno de los dos bandos se ha presentado ningún tipo de objeción respecto a la pertinencia de dicho cuestionamiento. Esa sobredosis de piedad pública, como lo cataloga el Washington Post, tiene que ver, nos lo señala la autora del artículo en Le Monde, con las exigencias impuestas por la movilización de las bases más radicales de las comunidades de fe que son, también, las que más se movilizan y las que mayoritariamente se desplazan para votar.

Es cierto que los "Padres Fundadores" inscribieron la libertad de religión en el texto constitucional de ese país. Esa libertad que, en el contexto de las sociedades secularizadas como la francesa o la mexicana, ${ }^{13}$ reconoce sobre todo el derecho inalienable a no tener religión y a excluir las consideraciones de ese orden de los asuntos públicos. Libertad entonces que, en el contexto de los debates, a lo largo del territorio de la Unión, se entiende perfectamente compatible con la religiosidad. Baste referir, para mostrar la relevancia de este caso, las palabras de uno de los contendientes, Mitt Romney, respecto a esa relación: “De la misma manera en que la religión tiene necesidad de la libertad, la libertad tiene necesidad de la religión".

\section{3.- El salvavidas de la ética. Un aspecto del caso francés}

$\mathrm{Al}$ principio de este escrito me he referido al efecto analizante que la Guerra de Argelia tuvo para sectores amplios de la izquierda francesa. El conciliar reivindicación nacional con transformación radical de la sociedad había desentonado sólo en un principio. Las cosas se empeoraron a la vista de la evolución que había tenido la vanguardia del movimiento en la ex colonia. La interrogante consistía en cómo ser crítico respecto a la burocratización de esta vanguardia, sin ser identificado de inmediato con un sucio colonialista. Ante esta disyuntiva se abrió paso, para amplios sectores de la izquierda francesa continental, el denominado "apoyo crítico" a dictadores "de izquierda" (Curtis, 2008: 1). Ese apoyo no tardaría en confluir en la ideología tercermundista del "hombre nuevo" y en la tentación que conlleva el sustituir al proletariado industrial — ya sólo interesado por luchar para consumir más - por el campesinado del tercer mundo, en un acto de clara indigencia teórica (Castoriadis, 1986: 130), por decir lo menos.

En el horizonte de esta evolución, dos de las grandes empresas políticas del siglo tuvieron un desenlace trágico, el estalinismo y el nazismo. En medios pro capitalistas, el fracaso del socialismo real se traducía, mecánicamente, en el triunfo de la sociedad de consumo. Mientras tanto en medios antaño combativos, particularmente en aquellos vinculados a la cultura católica, la ausencia de un proyecto político claro había conducido a amplios sectores a refugiarse en el reclamo de aquello que, genéricamente, se denomina la ética. La postura "antisistema", ${ }^{14}$ ya reivindicada por Stalin y Pol Pot, por sólo citar dos ejemplos tristemente célebres, se encontraba con el reclamo de la "ética", en un cruce de caminos. En ese cruce habían coincidido quienes se reconocían en la ética de la posmodernidad y aquellos que se posicionaban frente a la metafísica occidental y el "racionalismo falocrático".

En esa época Castoriadis asiste y acompaña la autodisolución (Castoriadis, 1967) del grupo y la revista Socialisme ou Barbarie. Según sus propias palabras (Gotraux, 1997), en ese entonces, él se sumergeenel psicoanálisis y en la filosofía. El desenlace de ese período, en el que Castoriadis se hace analizar además de incursionar en el saber psicoanalítico, será la formulación de sus nociones de imaginario radical y de alteridad. Parte de este esfuerzo lo va a llevar a un abordaje complejo del fenómeno religioso que nos ocupa. En ese lapso había 
tenido lugar el movimiento del 68, de cuyas enormes consecuencias, ampliamente documentadas, en particular a la hora de su cuarenta aniversario, no podemos ocuparnos en este espacio.

Son estos algunos de los elementos del contexto en el que, en los años sesenta, el filósofo francés de origen lituano, Emmanuel Levinas (1905-1995), había pasado, como profesor de filosofía, por varias universidades francesas (Poitiers, Nanterre y Sorbonne). Su propósito declarado era aquel de fundar una ética de la alteridad. Discípulo de Husserl y de Heidegger, Levinas había criticado la filosofía occidental — sólo preocupada, según él, por el saber y desdeñosa respecto a la búsqueda del "bien"reivindicando la relación no violenta del sí Mismo con el Otro, como vía posible hacia una auténtica trascendencia. Hagamos un paréntesis para dejar asentadas algunas de las líneas principales del pensamiento levinasiano.

Ampliamente leído y popularizado en Francia, el pensamiento de Levinas formula que el rostro del absolutamente otro impone la relación ética y conduce a Dios. El autor desarrolla su teoría gracias a abundantes comentarios provenientes de los Talmudes, ${ }^{15}$ con los cuales ubica a Dios por encima de la ley observada. En su obra Totalité et Infinie (1961), Levinas desarrolla la idea según la cual el deber frente al Otro es incondicional y es ése el que funda la humanidad del Hombre. Es importante notar en este punto que Levinas encuentra su fuente de inspiración mayor en el judaísmo, como religión ética. No obstante, esta fuente de inspiración va a ser, en los medios cristianos ${ }^{16}$ y gracias a una cierta "desmitologización" de Dios, en donde este autor va a encontrar mayor eco. Así pues, mientras que responder al otro es inmediatamente responder a la llamada de Dios, la ética de Levinas, como todas las éticas religiosas, trasciende la muerte, rechaza toda violencia respecto del otro y promete al hombre el ser, en tanto que "cara a cara", más allá de la esencia.

Al reconocer un sentido, si no mítico al menos divino en la alteridad, el infinito como él lo llama, la ética de Levinas es incapaz de asumir la alteridad plena. La doctrina cris- tiana, al profesar el amor al prójimo, tampoco logra despojar a éste de un sentido per se. Dicha tradición es incapaz entonces de ver al prójimo como instancia escindida, distinta de una simple variante de lo mismo. Es decir, de ver al prójimo como ser y simultáneamente como por-ser y (en esa medida) como alteridad radical. Tradición incapaz, entonces, de concebir la escisión del ser y del sujeto, manifestación del caos y de la alteridad que lo habita, de lo sin fondo, del sentido en el no sentido, de la muerte en la vida, del sexo en el amor, etcétera.

La concepción de la alteridad que asigna un sentido al ser, ligando ser y sentido, como en Levinas, por ese acto se clausura, es incapaz de concebir la creación noteológica. ${ }^{17}$ Esas concepciones, al conceder sentido per se a la alteridad y al ser, niegan la alteridad absoluta. Niegan ésta en su calidad de emergencia de lo radicalmente nuevo, que, per se, stricto sensu, no tiene sentido alguno. Esta denegación obliga a quienes sostienen esa postura a poner por delante a la ética, en detrimento de la política.

La situación descrita va a dar la pauta a Castoriadis para abordar la complejidad del fenómeno religioso. La ética como fórmula para mediar la relación con el otro, con la alteridad del otro, digamos, es vista por Castoriadis (Castoriadis, 1996: 206) como temática de sustitución del debate que supone vislumbrar un verdadero proyecto político. Parece claro que en el regreso ofensivo de dicha temática, en los últimos treinta años, subyace una reacción excesiva frente a los horrores de la política, en la historia reciente. Al mismo tiempo, es cierto que ese llamado sirve actualmente de recipiente para cualquier tipo de contenido que debe, en principio, ser bien visto en la medida en que interpone ante sus interlocutores el justificativo supuesto de "la ética". ${ }^{18}$ Cierro el paréntesis.

Los elementos expuestos conducen a preguntarse, teniendo a la vista este aspecto de la evolución de la religiosidad en Francia: ¿de cuál ética estamos hablando? ${ }^{19}$ Castoriadis (1996: 206) nos dice que el regreso a la cuestión de la ética denota, en todo caso, un malestar y una interrogación profunda, no asumidos. Lo anterior 
se verifica, al tiempo que la política ${ }^{20}$ sufre un enorme descrédito. Me refiero a la política entendida como alternativa a la violencia para dirimir diferencias, respecto a la manera en que las instituciones deben cambiar. ${ }^{21}$ Esa política persiste en un contexto en el que, ante los embates contemporáneos de las expresiones de intereses particulares, por las comunidades de pertenencia, la cosa pública y el vilipendiado, es cierto, bien común no despiertan interés alguno. Detengámonos a ver las implicaciones de esta pérdida de interés y de esta privatización creciente, que conlleva al auge de la toma de posición por la ética.

En la sociedad contemporánea crecientemente burocratizada, ante la incompetencia de los políticos profesionales, el término política se asocia también con prácticas de dudosa honorabilidad. A esa situación subyace la profunda crisis de valores que caracteriza a una sociedad a la deriva (Castoriadis, 2006: 281). Valores que, en la medida en que involucran el sentido, son significaciones imaginarias sociales que habían mantenido a la sociedad occidental unida. Hoy el efecto de cohesión de esas SIS ha sido cancelado por la incapacidad de autolimitarse que caracteriza a la matriz pseudo-racional.

En síntesis, la crisis de la metafísica greco-occidental, en tanto que clausura, "onto-theolo-logo-phallocentrica" (Heidegger citado por Castoriadis en MI, 1996: 208), viene acompañada del rechazo aludido de la política. Rechazo de la gran política ${ }^{22}$ que se expresa en un repliegue masivo en el espacio de lo privado que puede tener también el rostro de la comunidad de fe o de pertenencia, como veremos. Repliegue respecto del cual el llamado a la "ética" resulta particularmente funcional, en detrimento de las instancias en las que la sociedad se auto-altera de modo explícito.

La crítica de Castoriadis a esta postura, que es considerada consubstancial al llamado a la ética, va en el sentido de que hay en ella un supuesto implícito que es falso, en principio. Se trata de la fantasía de que nosotros somos individuos flotando libremente, por encima de la sociedad y de la historia y que cuando decidimos lo hacemos de modo so- berano y ubicándonos en el campo de lo absoluto. Esa supuesta condición ética, sustraída de la sociedad, escamotea interrogaciones tan fundamentales como: ¿Cuándo debo decir la verdad?, la respuesta a esta pregunta es del orden de la ética pero lo es también y antes que nada del orden de la política. No hay en este sentido ninguna regla abstracta que nos dispense de la responsabilidad de nuestras acciones.

Las morales religiosas y casi todas las morales filosóficas, la de Levinas incluida, desconocen u ocultan la dimensión trágica de la existencia, es decir, son morales dichosas (Castoriadis, 1996: 212). Pero cabe preguntarse, por sólo dar un ejemplo entre millones: zqué decir de situaciones en las que matar a alguien es la condición para salvar a otros?, como pudo haber ocurrido durante la resistencia en contra de los nazis, en la segunda guerra mundial.

Es cierto que en la filosofía moral de Kant - fundada sobre la libertad y sobre la autonomía de la voluntad, opuesta a la heteronomía-, el formalismo del actuar aparece como regido por el universalismo. Pero iqué decir del "homicidio" durante los conflictos bélicos?, iqué decir de la bendición de las armas, durante las guerras de los cruzados? Estas situaciones mostrarán que la razón de Estado es infinitamente más fuerte que la razón práctica y más fuerte que los diez mandamientos, no matarás, amarás a tu prójimo como a ti mismo, etcétera. En este contexto, ¿qué puede querer decir la fórmula levinasiana ética de la alteridad? y zen qué medida la obligación de "amar al prójimo", amar al otro, a autrui, porque "debemos" amarlos (Castoriadis, MI, 1996: 121), contradice radicalmente lo que nosotros entendemos por amor?

\section{2.- El pueblo de una religión}

Las dos situaciones ilustradas, que describen la manera como un pueblo vive la religiosidad y en particular las implicaciones del regreso de la ética, que acompaña la popularidad de pensamientos como el levinasiano en Francia, nos remite desde Castoriadis a la reconsidera- 
ción del lugar social e histórico en el cual nos ubicamos. Lugar social e histórico que necesariamente conlleva una manera particular de posicionarse frente a la institución, sagrada en unos casos, perfectible o incluso obsoleta en otros. Retomando la crítica de Levinas al privilegio de laverdad en la tradición de Occidente, ubicado en el terreno de la historia, Castoriadis argumenta que en el mundo griego clásico el término verdad no encuentra oposición entre lo privado y lo público, ni entre lo ético y lo político.

Las virtudes supremas del hombre son las virtudes cívicas y políticas. Sucesivamente el nacimiento de la filantropía, la oposición entre los ámbitos de lo político y lo ético, comienza con la derrota de Atenas (Castoriadis, 2006: 288). En la teoría — aun cuando todavía no en los hechos-dicha oposición entre ética y política empieza con Platón y su condena de la cité, la ciudad efectiva.

Lo que se anuncia para esa tradición, una vez acaecida la ruina de Esparta y de Atenas, será, con los cínicos y sobre todo los estoicos, el repliegue sobre la esfera privada. En ese sentido Aristóteles había reflexionado ya y escrito con anterioridad, en un contexto de crisis y disolución del mundo de la polis. Él se preguntará si es la misma cosa ser un buen hombre que ser un buen ciudadano; a lo que no encontrará respuesta categórica. Lo que viene después es un cierto olvido de esa reflexión, en laética de losestoicos, precisamente, hasta llegar a Roma y al propio cristianismo. Inmenso tema. No obstante, es ya plausible, para nuestro propósito, predecir ahí una fractura que advendrá entre el primer cristianismo del orden del imaginario social instituyente y el cristianismo instituido del siglo IV.

Inmenso tema en particular porque es a partir de ese siglo, nos dice el autor, que el cristianismo se institucionaliza y se convierte en religión de Estado, religión obligatoria para los habitantes del imperio. Se institucionaliza, a través de un formidable compromiso, en no pocas veces con el apoyo del filo de la espada. Compromiso ante el cual la ley moral nos es dada por otro, lo que marcaría que estu- viéramos ya desde entonces ante una ética heterónoma. El proceso de institucionalización de la religión traerá consigo, no puede ser de otra manera, la representación de un pueblo, el pueblo de la religión de que se trate. Si seguimos el razonamiento anterior, que se refiere al ser unitario y por tanto al ser social como siervo del señor, ese pueblo no puede ser de otro modo más que sumido en la aceptación incondicional de la heteronomía.

Al mismo tiempo, sabemos que dicha condición transferencial, en ningún caso, es posible al ciento por ciento. Es decir que toda tradición viene a ser, en un cierto punto, puesta explícita o implícitamente en tela de juicio, con lo que se abre por esta vía la alteridad radical. A partir de este punto se puede ya recurrir a algunas de las claves que plantea la noción de la alteridad para analizar el fenómeno religioso y para analizar la manera en que esa noción es enfrentada por cada sociedad.

\section{3.- Tiempo como alteridad-alteración y sentido como clausura}

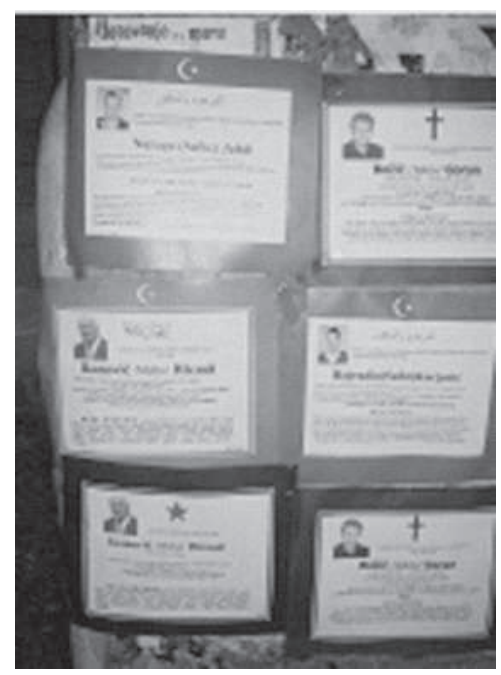

En la plaza pública de un pueblo de Bosnia Herzegovina en la ex-Yugoslavia. Se trata de notas necrológicas por filiación, ver abajo a la izquierda (fotografía de Rafael Miranda). 
Buscando desentrañar los aspectos menos visibles del fenómeno religioso, Castoriadis recurre a muchos de los planteamientos que, años atrás, cuando abordara la cuestión del fenómeno burocrático, le habían permitido concebir la dimensión imaginaria de la sociedad como un ámbito no reflejo. ${ }^{23}$

La crítica de dicho fenómeno, ceñido a la condición del imaginario y a su inclinación por la repetición, ${ }^{24}$ conlleva el paradigma de la creación, cuya temática había sido ignorada por la tradición filosófica. La creación sería la condición de lo emergente y por tanto de aquello que define al ser y al tiempo. La sociedad en este sentido emerge del caos como institución y es ésta la que hace posible que aquella permanezca unida. La institución, como magma de significaciones imaginarias sociales, emerge como posicionamiento de un mundo que es El mundo y en cuyo centro se encuentra la sociedad de que se trate, su tiempo calendario e imaginario, su nos-otros y su los otros.

Es este $m a g m a^{25}$ el ámbito por excelencia, en el que se niega el tiempo como alteridad-alteración, ${ }^{26} \mathrm{crea}$ ción y destrucción, para cada sociedad. Es el ámbito también en el que serán concebidas la simultaneidad y la equivalencia, entre el origen del mundo y el origen de la sociedad. Este posicionamiento por parte de cada sociedad, reitero, que se presenta bajo la forma de una clausura, aspira a recubrir el caos del que la sociedad emerge y el caos que ella contiene y representa. Con este posicionamiento se constituye la forma social del fenómeno religioso. Aquello que Casrtoriadis (1975: cap. VI) encuentra en el origen de la representación como creación, ${ }^{27}$ facultad del imaginario radical, es inconcebible desde el punto de vista del materialismo histórico y del positivismo científico y de sus destinos contemporáneos respectivos. Creación inconcebible también, como se desprende de lo dicho, para el pensamiento religioso.

Los desarrollos postmodernos en boga, referidos en páginas anteriores, tampoco estarían en condiciones de concebir tal creación. La unidad del ser y del sentido ${ }^{28}$ constituye para ellos el impedimento por excelencia. Las formas en las que se materializa la tradición filosófica heredada en el mundo contemporáneo, la ausencia de una filosofía política verdadera o a través de su reducción a una ciencia más, denotan la negativa implícita, aquí el punto central de nuestro argumento, de concebir la total destrucción. Es esa misma negativa de aceptar la extinción completa del sentido, como correlato de la muerte, la que conlleva aceptar la posibilidad de la creación. Esta negativa es, por excelencia, lo que caracteriza la relación entre instituyente e instituido en la sociedad religiosa.

Que la muerte sea siempre la muerte del otro ilustra aquellos destinos en los que la tradición mencionada ha coincidido con la forma de negar y ocultar la alteridad-alteración; forma que, de nuevo, expresa la naturaleza del fenómeno religioso. En el plano de la dimensión imaginaria radical, del que nos ocuparemos a continuación, como en aquel del imaginario social, esa coincidencia se repite. La institución, entonces, salvo en un caso paradigmático, tiene que erigirse, aun cuando sea vagamente, por encima del quehacer de los hombres concretos y las mujeres concretas. Al llegar a este punto es ya posible retomar las ideas matrices del pensamiento castoridiano respecto al fenómeno religioso.

\section{El núcleo duro del fenómeno religioso}

Hemos dicho, parafraseando a Castoriadis, que la sociedad emerge del caos. Emerge como un para sí, como institución social. Esta institución, en su condición de clausura, es la que - cuando se trata de la sociedad heterónoma o de repetición - garantiza, a través de la metanorma y de la fabricación del tipo antropológico que corresponde a su institución, el ocultamiento de la alteridad y de la perpetua auto-alteración. Paralelamente, en el curso de dicha fabricación, tiene lugar el cruce entre la institución social específica y el imaginario radical del sujeto individual. Esquemáticamente digamos que el conflicto por excelencia que caracteriza la ruptura del para-si, contenido en dicha clausura - ruptura operada por la emergencia de la psique humana-, no es un conflicto entre "el individuo" y la sociedad. El verdadero 
conflicto que subyace al hecho humano es aquel entre la psique y la significación imaginaria social del individuo. El individuo, socializado-fabricado, es ya y no puede ser más que individuo social.

Durante dicho proceso, la psique tiene que renunciar a sus objetos originales con los que fue investida. ${ }^{29}$ Son esos "objetos", la simultánea equivalencia de yo y todo, los que constituyen el estado monádico ${ }^{30}$ de la psique que no admite separación alguna y es en éste donde se verifica la completa indiferenciación entre sî misma y todo. El odio racial está fundado precisamente en aquello que la psique experimenta respecto al sî misma como otro, el individuo social (Castoriadis, 1999: 186). El complemento necesario para que dicho odio se materialice, con el deseo inalienable de supresión del otro como otro, estará dado por las significaciones imaginarias sociales. SIS históricamente disponibles e igualmente fundadas en la clausura de la sociedad heterónoma. SIS equivalentes, en su relación con la institución y con la alteridad, en las que subyace el delirio antisemita, la denominada limpieza étnica, incluida la violación como arma de guerra, la misoginia, de Treblinka a Sarajevo, a los Grandes Lagos y a Srebrenica.

Otras formas de intolerancia del otro estarán mayormente ligadas al odio que la psique va a experimentar respecto al otro real. Castoriadis (1975: cap. VI) refiere a Melanie Klein cuando habla de la representación del recién nacido dentro del "seno malo" y del "seno bueno". Se trata en este caso del otro real primordial, la madre amadaodiada. En efecto, contrario a aquello que Freud había vaticinado al referirse al odio del primer objeto exterior, el amor es anterior al odio. El amor de sí, no el amor de objeto, precede a toda separación en el caso del estado monádico de la psique, que me ocupa en estas líneas. Este estado será roto por el proceso de socialización y tendrá como primer resultado la transferencia del esquema de omnipotencia, ${ }^{31}$ de sí, hacia el otro. La madre y posteriormente el padre serán dueños y señores del sentido, le seguirán las instituciones, la ciencia, el partido, la comunidad, el caudillo, la patria y finalmente la Iglesia.
Es en estos términos expuestos, concentrados y esquemáticos, que Castoriadis va a ubicar el deseo de clausura, que caracteriza a las sociedades de repetición. Es ese deseo, o incluso esa necesidad, lo que va a inspirar la exterioridad supuesta del origen de la institución social. Es ese deseo el que subyace en el contenido de la sublimación a la hora de socializar a cada tipo antropológico de que se trate. Las instituciones garantes, que permiten el recubrimiento del caos fuera y dentro de la propia sociedad y de la alteridad-alteración, son las mismas que hacen posible que el sujeto se oculte a sí mismo y, de modo equivalente, que oculte el caos que lo habita y el caos que él representa. Veamos ahora, para cerrar, algunos de los efectos de lo dicho en este parágrafo para el campo del quehacer instituyente y de la acción social.

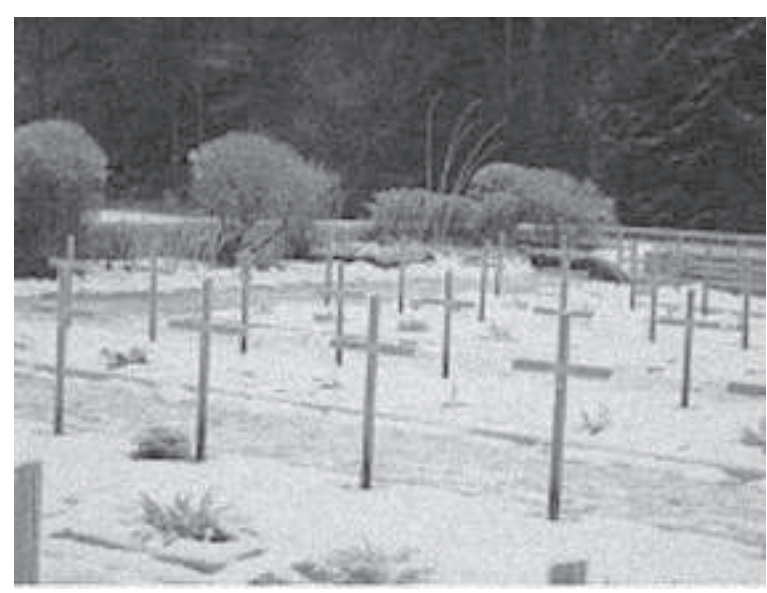

Cementerio de la Resistencia Francesa en las inmediaciones de Annecy. Figuran por filiación, entre los caídos del Plateau de Glières, al lado de los franceses, algunos alemanes combatientes contra el nazismo, polacos y un número importante de españoles antifranquistas (fotografía de Rafael Miranda).

\section{Nota sobre transferencia institucional y política}

Las nociones por medio de las cuales se analiza la manera de vivir la religión, por parte de un pueblo, contienen el modo como se concibe la sociedad. Nos 
hemos referido a la tendencia, en el contexto de lo que Castoriadis denomina la ideología francesa, hacia un cierto angelismo subyacente en la apuesta que se hace sobre la ética. En el apartado inicial de este escrito, se hizo mención al modo como se vive la religión en los Estados Unidos. En ese contexto, subrayamos la necesidad de entender que cuando se nos habla de las comunidades es necesario pensar que se trata de entidades sujetas a un proceso caracterizado por el conflicto, soterrado si se quiere. Se nos habla no de una unidad sino de un proceso de auto-alteración, subyacente a un tipo de relación específica entre el instituyente y el instituido. Auto alteración implícita y cubierta por un velo, generalmente operada por líderes, como portavoces auto designados o corroborados tácitamente por la renuncia del colectivo anónimo. ${ }^{32}$ No obstante, la versión de este proceso en la cultura política del caudillismo —-de izquierda" o "de derecha"-, en América Latina, nos brinda un ejemplo elocuentísimo, el cual exige un tratamiento que excedería por mucho los límites de la presente contribución.

Aquello que puede llamarse la transferencia institucional, ese estado regresivo en el que la transferencia del esquema de omnipotencia encuentra recipiente, ya no en el primer objeto externo, sino en la propia institución, tiene una importancia capital para nuestra exposición. La institución que todo lo puede, esa promesa de transferencia absoluta tan presente en la religiosidad extrema, regresa, una y otra vez, en los momentos en los que la sociedad ha dado la espalda a la propia facultad y al ejercicio explícito de auto-instituirse.

De esta relación de transferencia al cien por ciento con la institución y de sus estrechos lazos con las condiciones dadas por el estado monádico de la psique, me he ocupado en otro espacio (Miranda, 2002). Para el propósito presente es importante insistir en que en la transferencia del esquema de omnipotencia de la psique, en estado original, en el que éste pase de ser una simple intolerancia del otro como otro y se convierta en la necesidad improrrogable de su supresión, la disponibilidad histórica de significaciones imaginarias es de primer orden. Esas significaciones son creaciones del imaginario instituyente $y$, salvo en el caso paradigmático representado por la sociedad autónoma en proyecto nacida a la par de la filosofía que se sabe tal y de la democracia, su origen es identificado con una instancia extra-social.

En el contexto de dicho nacimiento, considerado como un germen y no como un modelo, Castoriadis va a discutir la división tradicional de la sociedad, en sociedad civil y Estado, con el argumento de que dicho esquema es inexacto. Existiría para él un estado intermedio propiamente, una instancia privada-pública. En efecto, al proponer, inspirado en la Atenas democrática, la división entre el espacio privado —el Oikos-, el espacio privado-público —el Ágora - y el espacio propiamente político - laEclesia-, el autor nos brinda una herramienta preciada a la hora de descifrar el mundo contemporáneo.

El espacio del ágora, el lugar de la confrontación de las doxas, las opiniones, con base en el principio de que "debemos respetar las leyes, pero podemos cambiarlas", es el lugar en donde se expresa la autonomía y la autonomía de los otros. Es igualmente en ese espacio en donde se juega el contenido de la sublimación, por el cual se socializa al tipo antropológico de la sociedad autónoma en proyecto. Es ahí en donde se trabaja, gracias a la paideia, la formación del filósofo ciudadano. Ahí en donde, gracias al psicoanálisis - cuyo fin en los dos sentidos es la autonomía del sujeto-, se trabaja por la autonomía, a partir de una autonomía que todavía no existe.

La ocupación masiva del ágora, ese espacio públicoprivado anterior al espacio propiamente político, por la expresión de los intereses particulares de las comunidades de pertenencia que vemos hoy, en el mundo contemporáneo, ha traído consigo un empobrecimiento mayúsculo de la cultura política. Este empobrecimiento cuadra perfectamente, es funcional diría yo, con el slogan del regreso de lo religioso y con el llamado de la ética. Se trata del efecto de la privatización del individuo, derivada 
de la significación del dominio pseudo-racional por un lado; por el otro, encontramos el mimetismo identitario con la propia comunidad.

Las dos tendencias son funcionales a la de-socialización, llevada a cabo por el sistema capitalista, que convierte al sujeto en un simple consumidor compulsivo. Este proceso viene hoy acompañado, no casualmente, de la presencia masiva de expertos y de líderes de comunidades de fe. Esa tendencia cierra el círculo del despojo de la política, como lugar de transformación explícita de las instituciones, por parte del colectivo anónimo. La negación entonces de la sociedad instituyente, 33 la vuelta a "la ética" y el repliegue sobre el espacio privado, por ejemplo a través del misticismo, son la otra cara de la moneda del proceso descrito. Todo este movimiento está permeado por el fenómeno religioso, como lo hemos analizado.

Digámoslo claro: finalmente, toda sociedad se autoconstituye y se auto-altera, algunas sociedades lo hacen explícitamente, otras no. El valor que subyace a la autoinstitución explícita es el mismo que, por definición, nos obliga a interrogarnos radicalmente respecto a nuestras propias instituciones. Ni sólo en nombre de la universalidad, ni sólo en nombre de la episteme. Es la doxa, el decir y la filia, el afecto en sentido fuerte, basado en el reconocimiento recíproco del otro, ni más, ni igual, ni menos, sino del otro como otro, lo que nos autoriza y nos obliga, por coherencia, a preguntarnos sobre las instituciones propias y ajenas. El devenir como alteridad y caos no es per se ni inocente ni diabólico; ese devenir debe ser enfrentado y su limitación sometida a la pregunta: ies ésta la ley que más me conviene? No podemos eludir esa responsabilidad. Dicha interrogación más que del orden de la ética, es del orden de la política y del infrapoder. ${ }^{34}$ Infrapoder que es lugar de creación de sentido nuevo, que subyace a la instancia del poder explícito. Es ese infrapoder la materia que emerge en el ágora, la materia del espacio privado-público, hoy acosado por los comunitarismos. A despecho de quienes piensan, como Mitt Romney que "como la religión tiene necesidad de libertad, la libertad tiene necesidad de religión", dejémoslo claro: las certezas incuestionables, las verdades eternas y las metanormas, que sustentan la heteronomía social, pertenecen a otro orden. En nada se parecen al lugar de la deliberación radical y en consecuencia, por definición y principio involuntario, van a contracorriente del proyecto de la sociedad autónoma.

\section{Notas}

${ }^{1}$ Quiero dejar aquí testimonio de mi agradecimiento, por la lectura atenta y las sugerencias, a Mercedes Olivera y Luis Antonio Sánchez Trujillo. Claramente, los contenidos, errores y horrores de este texto son, por entero, mi responsabilidad.

${ }^{2}$ Las SIS son una categoría central del modo en el que Castoriadis entiende la cuestión de la circulación del sentido, no entre individuo y sociedad, visto que el individuo es por naturaleza ya social, sino la circulación de sentido entre la psique y la sociedad. Los dos elementos de la significación son pues irreductibles el uno respecto al otro y coexisten en su dimensión tanto individual como social en una relación caracterizada por la tensión.

${ }^{3}$ En contraposición a heterónomos, que la ley me sea dictada por el otro.

${ }^{4}$ En este contexto entiendo por ciudad la cité grecque en francés, es decir polis en griego, diferenciándola de la traducción de los anglosajones, city state (ciudad estado) que introduce el equívoco, señalado por Castoriadis, según el cual se trataría ahí de un Estado (Vidal-Naquet, 1999: 133).

${ }^{5}$ La clausura como sentido tiene en Castoriadis una importancia capital. No obstante, el fundamento de esa clausura se encuentra en el estado monádico de la psique original; gracias al esquema que liga en una relación irreductible imaginario y social, cobra su máxima expresión en el terreno de lo social histórico en las sociedades de repetición o religiosas.

${ }^{6}$ La transferencia es desde el cuerpo conceptual del psicoanálisis un estado regresivo por el cual el analizado en la situación analítica revive el amor o el odio hacia la figura paterna depositándolo en la persona del ana- 
lista. La transferencia institucional es una extensión de dicha regresión sólo que en este caso su depositario es una institución social: el partido, la iglesia, la empresa, la comunidad de pertenencia, la ciencia, etcétera.

${ }^{7}$ Más allá de la simple declaración sobre la realidad de la ex-URSS como un Estado obrero degenerado, por los partidos trotskistas, por ejemplo.

${ }^{8}$ Rene Lourau entiende el carácter analizante de un evento, también, como imaginario social instituyente, ver la bibliografía propuesta, a partir del momento en que ese desencadena una serie de cuestionamientos profundos, dirigidos a instituciones que antes del evento eran incuestionables. El modo como este autor recupera de Castoriadis la noción de institución es como magma de significaciones imaginarias sociales, haciendo una diferenciación neta entre institución (la Iglesia por ejemplo) y establecimiento (la Diócesis de $x$ provincia)

${ }^{9}$ Entiendo por metanorma la "norma de normas" incuestionable y pretendidamente dictada por una instancia extrasocial y por tanto inalcanzable: la naturaleza, los dioses, los antepasados que ya no están, las leyes de la historia o aquellas del mercado.

${ }^{10}$ Entiendo aquí por alteridad radical la emergencia de lo nuevo que define al tiempo, al ser y a la historia. Diferencio la alteridad de la simple otredad, en virtud de que ésta, no obstante, se refiere a la condición de lo otro; es menos enfática respecto a la alteración.

${ }^{11}$ Anotemos en relación con este punto, con el fin de disipar un malentendido frecuente, que, contrario a lo que se piensa en medios académicos particularmente mexicanos y españoles, para Castoriadis la idea de un pensamiento posmoderno es una idea ajena, por decir lo menos. En medios allegados a Castoriadis, al referirse a la sociedad autónoma en proyecto, se habla más bien de una segunda modernidad, basada en el valor de la autonomía y no más en el dominio racional.

${ }^{12}$ http://pewresearch.org/pubs/

${ }^{13}$ La libertad de culto es prevista en Francia por la Ley -después de un largo proceso que se inicia poco antes de la Revolución Francesa-. La separación de la Iglesia
Católica y el Estado se concreta en ese país en 1880, por obra de la III eme Republique; en México, siendo presidente Benito Juárez, indígena zapoteco, son declaradas las Leyes de Reforma, que separan la Iglesia Católica del Estado, en 1858.

${ }^{14}$ Panacea, en el presente, del movimiento altermundialista.

15 "Enseñanza" en hebreo moderno, recopilación de derecho civil y religioso judío.

${ }^{16}$ Notemos que estas dos tradiciones son aquellas que más han estado expuestas al proyecto de autonomía.

${ }^{17}$ La supuesta "creación teológica" no es claramente una creación puesto que "el mundo es creado por Dios a su imagen y semejanza".

${ }^{18}$ Un caso de esas acciones "irreprochables", que recuerdan la tristemente célebre frase de los jesuitas cuando, al hablar de las poblaciones a las que asistían decían "mis pobres", es el del Arca de Zoe. Están ahí presentes los reclamos de "la ética" por parte de comunidades de pertenencia que como tales embisten el espacio público. Una vez que se hizo la encuesta sobre las acciones temerarias de esa ONG, basada en Francia, se rebeló un hecho que mezcla "compasión por los pobres", manipulación de los "buenos deseos" de familias continentales deseosas de adoptar a un menor, arrogancia y desprecio frente a las autoridades de un país desastrado y prácticas de tráfico de menores con fines de lucro. Ver en bibliografía Le Monde, noviembre 06 de 2007.

${ }^{19}$ ¿De la ética protestante? ¿De aquella posmoderna? o ¿de aquella de la alteridad como la entiende Levinas?

${ }^{20}$ En tanto que un asunto de políticos profesionales y de expertos de la totalidad.

${ }^{21}$ Como de hecho ocurrió en el caso de las revoluciones francesa y americana.

${ }^{22}$ Sustancialmente distinta a la ocupación profesional de "los políticos".

${ }^{23}$ El imaginario en Castoriadis no es y no puede ser un reflejo de la estructura o la expresión de quien sabe qué determinismo biológico, psíquico, histórico u otro. El imaginario para él es una instancia no determinada sino determinante fuente de creaciones en sentido fuerte. 
${ }^{24}$ Uso este término como se emplea en teoría psicoanalítica, es decir, como correlato de la pulsión, véase la compulsión de repetición. Con el propósito de disipar eventuales confusiones, en lo que resta de este escrito, para lectores no familiarizados con la obra castoridiana, aclaro que en ningún momento del desarrollo de ese pensamiento el psicoanálisis es considerado una ciencia, una episteme o una "pseudociencia". El psicoanálisis es para nuestro autor y en alguna medida - a pesar de la presión que el ambiente positivista de la época ejercía sobre él一, también para el propio Freud, un saber, no una ciencia, aunado a una práctica poietica es decir a una práctica de auto-creación. El propio Freud utilizaba la metáfora de religión sin dios, refiriéndose al psicoanálisis. Como veremos en adelante ese saber, en cuanto doxa, opinión, que hace o deja de hacer sentido, es parte fundante — con la formación del filósofo ciudadano y con la política en sentido noble, es decir, como medio para transformar las propias instituciones- del proyecto de autonomía.

${ }^{25}$ La noción de magma para nuestro autor constituye una vía alterna para evitar hablar de estructura, por ejemplo en lo que se refiere a la institución por excelencia, el lenguaje. La metáfora tectónica permite ilustrar una materia perennemente estratificada y susceptible de desbordarse a sí misma o de hacerse sólida. La institución social como hemos dicho es para nuestro autor un magma de significaciones imaginarias sociales.

${ }^{26}$ Antes que el positivismo científico, la obsesión por medir y por tanto controlar el tiempo encuentra sus orígenes en el minucioso trabajo de los primeros relojeros suizos, habitantes de las montañas del Jura.

${ }^{27}$ La representación como creación en Castoriadis es una idea que parte de la condición por excelencia de la psique humana que logra representar el objeto en su ausencia y obtener placer de la representación por encima e independientemente del órgano.

${ }^{28}$ Así como en el caso de la hermenéutica, la ciencia de la interpretación. El supuesto que subyace es que el sentido preexiste al texto y que la comprensión equivale a la reconstrucción -o en sentido inverso a la deconstrucción-, de la intención original del autor. La existencia de un sentido determinado del que hay que apropiarse o dar cuenta, es del mismo orden de cosas.

${ }^{29}$ La sublimación es un proceso en el cual la monada psíquica, originalmente clausurada, tiene que dar sentido a objetos externos socialmente disponibles, como condición para su ingreso en el mundo. En otro espacio (Miranda, 2008) desarrollo las implicaciones que conlleva una sublimación inspirada por la heteronomía en contraste con aquella que valora la autonomía.

${ }^{30}$ Estado originario de la psique anterior al proceso de separación que supone el establecimiento de un otro.

${ }^{31}$ El único que la psique, en la medida en que al representar simultáneamente realiza, conoce.

32 Esta instancia es identificada por Castoriadis como la sede en donde radica la auto transformación soterrada de la sociedad. Ver más adelante la noción de infrapoder.

${ }^{33} \mathrm{La}$ sociedad instituyente o el imaginario social constituye la forma mundana de la capacidad del imaginario radical de crear nuevas formas. Esa instancia se constituye en el cruce entre la institución social y el imaginario radical y representa el lugar de la formación de compromiso entre esas dos dimensiones del imaginario.

34 ...el poder instituyente, que es a la vez el del imaginario instituyente, el de la sociedad instituida y el de toda la historia que encuentra en ello su salida provisional. Es pues, en cierto sentido, el poder del campo histórico social mismo, el poder de outrui, de Nadie (Poder, política y autonomía: 4).

\section{Bibliografía}

Castoriadis, Cornelius, 2002, "Orígenes, sentido y alcance del proyecto filosófico", en Revista Archipiélago, Cuadernos de crítica de la cultura, diciembre, núm. 54, Barcelona.

—, 2006a, "Porque ya no soy marxista", en Una sociedad a la deriva, editorial Katz, Buenos Aires. 
—, 1982, "Con Daniel Cohn-Bendit y el público de Lovaina-la-Neuve", De la ecología a la autonomía, editorial Mascarón, Barcelona.

—, 1992a, "L'écologie est-elle réactionnaire? Sauvons les zappeurs abrutis", en Le Nouvel Observateur, mayo, Paris.

—, 1992b, "Le capitalisme est-il soluble dans l'écologie?", en Le Nouvel Observateur, Collection Dossiers (Demain la terre), junio, Paris.

—, 2006b, "La ecología contra los mercaderes", en Una sociedad a la deriva, editorial Katz, Buenos Aires.

—, 2007a, La suspension de la publication de Socialisme ou Barbarie ( «Circulaire adressée aux abonnés et lecteurs de Socialisme ou Barbarie en juin 1967»), http://www. agorainternational.org/suspsoub.pdf.

—, 1986a, "Psychanalyse et société", en Domaines de l'homme, Les carrefours du labyrinthe II, Éditions du Seuil, Paris.

—, 1990a, "Psicoanálisis y política", en Le Monde morcelé. Les carrefours dulabyrinthe III, Éditions du Seuil, Paris, http:// www.passant-ordinaire.com/revue/34-228.asp.

—, 1986b, "Institution de la société et religion”, en Domaines de l'homme. Les carrefours du labyrinthe II, Éditions du Seuil, Paris.

—, 1975a, "Imaginaire radical, société instituant, société institué", en L'Institution imaginaire de la société, Éditions du Seuil, Paris.

—, 1990b, "Reflexiones sobre el racismo", en El Mundo fragmentado, Editorial Nordan-Altamira, ArgentinaMontevideo.

—, 1995, "La democracia como procedimiento y como régimen", en Vuelta, octubre, núm. 227, México.

—, 1996a, "Le cache-misère de l'éthique", en La Montée de l'insignifiance. Les carrefours du labyrinthe IV, Éditions du Seuil, Paris.

—, 1996b, "Imaginaire politique grecque et moderne", en La Montée de linsignifiance. Les carrefours du labyrinthe IV, Éditions du Seuil, Paris.

—, 1977-1986, "L'imaginaire: la création dans le domaine social-historique", en Domines de l'homme. Les carrefours du Labirinthe, Éditions du Seuil, Paris.
—, 1975b, "La question de l'origine de la représentation", en Linstitution imaginaire de la societe, Éditions du Seuil, Paris. —, 1990b, "Pouvoir, politique, autonomie", en Le Monde morcelé. Les carrefours du labyrinthe III, Éditions du Seuil, Paris.

—, 2007b, Democraciay Relativismo, Debate con el MAUSS, editorial Trotta, Madrid.

—, 1998, «Les racines psychiques et sociales de la haine», en Guérir de la guerre et juger la paix, (Bajo la responsabilidad de Rada Ivekovic et de Jacques Poulin), Actas del Colloque International de Philosophie que tuvo lugar en la sede de la UNESCO del 21 au 23 juin 1995, L'Harmattan, Paris.

—, 1986c, "Tiers Monde, tiers-mondisme, démocratie", en Domaines de l'homme: Les carrefours du labyrinthe II, Éditions du Seuil, Paris.

Clastres, Pierre, 1974, La société contre l'Etat, ediciones De Minuit, Paris.

Curtis, David, Cornelius Castoriadis Dies 75, Philosopher and Political Thinker Inspired May'68 Rebellion in France, http://www.agorainternational.org/abouttext.html.

Eudes, Yves, 2007, Le desarroi des familles d'acceuil, en el periódico Le Monde, Paris.

Gottraux, Philippe, 1997, Socialisme ou Barbarie: Un engagement politique et intellectuel dans la France de l'après-guerre, Éditions Payot, Lausanne.

Deveraux, Georges, 1980, De l'angoisse a la méthode dans les sciences du comportement, editorial Flammarion, Paris.

Klein, Melanie y Riviere, Joan, 2001, L'amour et la haine, editorial Petite Bibliothèque Payot, Paris.

Levinas, Emmanuel, 1999, Totalidad e Infinito, editorial Sígueme, Salamanca.

Lesnes, Corine, 2007, Dieu domine le debat presidentiel americain, en periodico Le Monde, Paris, http://www. lemonde.fr/web/article/0,1-0@2-3222,36-993663,0. html.

Lourau, René, 1980, Autodissolution des avant-gardes, Éditions Galilée, Paris.

—, 1991, El análisis institucional, Amorrortu editores, Buenos Aires. 
—, 1974, L'analyseur Lip, Union Générale d'éditions, Paris. Lyotard, Jean Francois, 1989, La guerre des algériens, Ecrits 1953-1963, Editorial Galilée, Paris.

Miranda, Rafael, 2008, "El sujeto autónomo y la alteridad", en Fragmentos del caos. Filosofía, sujeto y sociedad, Cornelius Catoriadis, por Daniel H. Cabrera (coordinador), editorial Biblos, Buenos Aires.

—, 2004, "Les frontières de la haine. À propos de l'altérité selon Cornelius Castoriadis", en L'autre. Cliniques, cultures et sociétés, pp. 265-75, http://www.fundanin. org/mirandal.htm.
—, 2006, "Las Fronteras del odio. Reflexión sobre la alteridad a partir de Cornelius Castoriadis", en revista Tramas, Subjetividad y procesos sociales, UAM-X, México, 2006, http://tramas.xoc.uam.mx/tabla_contenido.php?id_fasciculo=65

Simon, Henri, 1979, "De la scission avec Socialisme ou Barbarie a la rupture avec I.C.O. " (entrevista), en L'Anti-mithes, núm. 6, Paris.

Vidal-Naquet, Pierre, 1999, «Castoriadis et la Grèce ancienne», enEsprit,Paris,núm. 259, diciembre, http://libertaire. free.fr/Castoriadis $48 . h t m l$. 